\title{
O signo sem sentido
}

$\frac{\text { LuCRECIA D Alessio FerRara }}{\text { Universidade Tuiuti do Paraná/UTP }}$ 


\section{Resumo}

Este artigo estuda a profunda transformação perceptiva que decorre da Revolução Industrial mecânica até a digital. Neste território analisa várias modalidades do Desenho Industrial (o desenho do objeto, a moda e o desenho têxtil) e demonstra a evolução que vai do valor de uso ao valor de troca (K. Marx) até a emergência de um valor de posse que se desenvolve até um valor de seleção da informação na caracterização de distintas relações comunicativas e culturais.

\section{Palavras-chave}

comunicação/informação, moda, design, cultura

\section{Abstract}

This article study the deep perception transformation build by the mechanical Industrial Revolution to the digital midia. In this field it analyse many examples of the industrial design (product design, fashion and textile design) and show the evolution of the use value to the change value (K. Marx) until the emergence of a kind of amass value and a informational selection value to define other cultural and comunicative relation.

\section{Key words}

comunication/information, fashion, design, culture 


\section{Sinergia cultural}

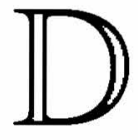

o estilista ao designer, da moda à tecnologia têxtil é de design que se trata e, por isso, talvez haja sentido em refletir sobre alguns aspectos culturais que configuram a essência da atividade.

O design não se explica com clareza, seu campo não se define com nitidez e a ambigüidade o caracteriza, pois se trata de uma prática que se relaciona com vários tipos da atividade humana. Essa constatação se justifica historicamente, porém não é preciso percorrer a história do desenho industrial, mas apenas, considerar aspectos culturais que são relevantes.

$\mathrm{O}$ desenho industrial está intensamente marcado pela revolução tecnológica, econômica, social e cultural que assinalou o mundo ocidental desde a segunda metade do século 18 quando James Watt (1769) aperfeiçoou a máquina a vapor. O novo elemento foi capaz de impulsionar o desenvolvimento da fiação manual e artesanal do algodão para a tecelagem manufaturada através de máquinas e da indústria pesada voltada para a mineração e para a metalurgia. Tinha início a Revolução Industrial mecânica.

Ora, a história da humanidade nos mostra que sempre que a tecnologia altera o modo de produção, desenvolvem-se novos valores, comportamentos e cotidianos. As tecnologias afetam as maneiras como pensamos e como agimos: se os meios de produção caracterizam a História Econômica, o domínio de um meio técnico caracteriza a História Social.

Nessa dinâmica, se o capitalismo se define pela emergência do capital e da máquina que permitiram o desenvolvimento de 
dicotomias como o patrão e o operário, o salário e o lucro; o mundo eletroeletrônico assinalou o domínio da imagem, da comunicação de massa e da sinestesia entre imagem, som e movimento e a tecnologia digital caracteriza a interconexão comunicativa, a simultaneidade e conseqüente compressão do tempo e do espaço e a mudança, não só rápida, mas sobretudo, definitiva e inexorável.

Desde tempos imemoriais, o artesanato caracterizou as sociedades pré-industriais e marcou-se pela produção de objetos, de um lado, indispensáveis à vida cotidiana e, de outro, criadores de valores, de crenças e de sociabilidades. Com o advento da Revolução Industrial Mecânica no século 18 e seu posterior desenvolvimento, temos a emergência de características produtivas relacionadas ao Desenho Industrial. Trata-se da racionalidade, do planejamento e do controle que estabelecem a lógica de transformação material e da reprodução em série e em montagem tecnológica.

Essas características tornam-se mais complexas quando, como decorrência da produção industrial acelerada, surge, na década de 40 do século 20, a necessidade de estimular a outra face da produção, ou seja, surge o consumo com seus derivados caracterizados pelo mercado e a publicidade: era necessário consumir para produzir e produzir para sobreviver.

Na correlação entre arte/desenho/produção/consumo temos, como decorrência, a possibilidade de atingir uma definição chave: design é a atividade que transforma a tecnologia no produto e, como informação, é capaz de atrair a percepção e construir a persuasão $e$ o consumo. Pela sua proposta criativa, o design constitui apoio para a célebre lei da oferta e da procura.

$\mathrm{Na}$ complexa relação entre arte e desenho; artesanato e tecnologia, objeto único e reprodutibilidade em série e em massa, produção e consumo, oferta e mercado, qualidade e persuasão surge a noção básica que coordena a atmosfera cultural dos nossos dias: sinergia.

Da sua etimologia grega (synergía) a palavra sinergia conserva o sentido de cooperação, ou seja, de um lado, o esforço combinado de vários organismos para a realização de uma função e, de outro, a associação simultânea de fatores que contribuem para uma ação coordenada. Sinergia propõe a contaminação entre ação e fun- 
ção, porém, no mundo da automação digital, essa relação deixa de ser linear para ser simultânea e, sobretudo, rápida. Estabelece-se um outro dispositivo cultural: tudo interage e todos se comunicam coletivamente. Essa interação entre propriedades em relação caracteriza a dinâmica produtiva atual exige uma outra forma de estudar os fenômenos. Porém, para entender a dinâmica cultural e social que atinge o Desenho Industrial dos nossos dias é necessário delinear a estrutura daquela sinergia e discriminar os elementos que a compõem.

\section{Da arte à tecnologia}

Walter Benjamin, filósofo alemão e um dos maiores intérpretes da cultura contemporânea, que se suicidou em 1940 em Port Bou quando tentava atravessar os Pirineus para chegar à Espanha fugindo do regime nazista e da perseguição étnica, publicou, em 1936, um artigo célebre que não pode ser esquecido pela fundamental compreensão da relação que se estabelece entre a arte e a tecnologia industrial ou da passagem do mundo artesanal para a produção em série e reprodução em massa. Esse artigo, "A obra de arte na época da sua reprodutibilidade técnica", deve ser constantemente retomado se quisermos entender o impacto cultural patrocinado pela revolução industrial da sua dimensão mecânica à eletrônica até à automação digital.

A passagem da qualidade do produto artesanal à quantidade da produção industrial encobre uma intensa revolução cultural que supõe a substituição do único modelado manualmente para o múltiplo funcional e anônimo. Além disso, supõe a passagem da produção de características religiosas e míticas onde se edificavam catedrais, esculpiam-se imagens de deuses e pintavam-se cenas religiosas que ornamentavam as paredes de igrejas, capelas e castelos para atingir a atmosfera da fábrica que marcou o desenvolvimento da concentração populacional em cidades e a emergência das metrópoles dos nossos dias. Embora esses fenômenos sejam distintos, do ponto de vista cultural é possível relacionar a arte e a indústria, assim como aproximar o artista e o desenhista industrial, embora seja necessário enfatizar que, se a arte privilegia a percepção e a contemplação, a indústria seleciona o produto e a produção. 
Da arte religiosa à indústria temos uma passagem radical, mas de prudente lentidão que caracteriza a substituição daquela contemplação pela utilidade, do culto religioso pela função pragmática.

A realidade econômica, social, cultural e tecnológica que vinha sendo intensamente concebida desde a segunda metade do século 18 , intensifica-se no século 19 com a invenção da fotografia (1839) e adquire cores definitivas nos anos posteriores à primeira grande guerra com a emergência do que se convencionou chamar de "época do funcionalismo" (Argan, 1993, p. 236) Ao desenhista industrial cabia a tarefa de explorar a tecnologia mecânica disponível para produzir a melhor qualidade com o menor desgaste de energia mecânica, material e humana e, para essa economia, havia a proposta de um só fator: a função.

A qualidade funcional resgata o cotidiano e lhe permite modelar a forma e o uso do produto e, sobretudo, superar o caráter contemplativo da arte para, de modo utilitário, permitir que a forma seja conduzida pela função e assinale um programa de recepção mecânica e rotineira.

Porém, na dinâmica industrial da montagem em série, o avanço da tecnologia dos materiais e seus procedimentos condenam os produtos a uma superação incontrolável. Desse modo, a história do desenho industrial já nasce atemporal porque não chega a marcar época: se o progresso tecnológico envolve a produção, a eficiência funcional é tragada pela forma que, por sua vez, cede ao mercado e à persuasão publicitária do consumo.

\section{Do uso à troca}

Da função à forma, da produção ao consumo e ao mercado, do possível tecnologicamente ao aceitável publicamente, escreve-se uma história de transformação da cultura e dos seus valores: uma intensa e rápida história que percorre estágios que vão do valor de uso funcional ao valor de troca comercial, da posse à seleção do objeto e o mundo da produção industrial passa a ser caracterizado pela relação comunicativa entre produção e consumo que encontra no objeto seu elemento de mediação e de linguagem. Nesse percur- 
so, o desenhista industrial cede seu espaço ao designer, isto é, o desenho industrial supera o uso funcional e se transforma no design que incorpora à competência técnica, a dimensão cultural que alia, à informação de outros usos, a sugestão comunicativa de outros valores. Precisamos entender a gênese e as características de cada um desses momentos.

No mundo capitalista, a mercadoria se divide em duas categorias divergentes: o valor de uso e o valor de troca. Se o valor de uso estabelece a relação entre o proprietário dos meios de produção e o operário que é o agente produtor, o valor de troca procura salvar a produção através do consumo, porém ambos, valor de uso e de troca, se encontram e desafiam no espaço do mercado onde "a lógica do produtor procura a massificação do valor de troca e a lógica do consumidor procura a valorização do uso." (Ferrara,1993, p.194) Estimula-se a compra para criar efetivas condições para a dinâmica produtiva e, nessa estratégia, a forma e as qualidades visuais do produto desenvolvem importante papel, porque se o valor de troca ensinou a consumir, não tardou para que ele fosse substituído pelo apelo que o distingue. Surge o valor de posse e passa-se a consumir não somente o produto, mas a griffe, a embalagem, o visual. Na passagem do valor de troca para o valor de posse percebe-se que, estranha e paradoxalmente, procura-se, na série, o único, o original, o exclusivo de marca que caracteriza a notabilidade da exibição que confirma a posse e retorna-se aos pressupostos que caracterizavam o culto artístico. Cria-se, assim, uma cadeia de substituições ou de metamorfoses do objeto, da série e da reprodutibilidade: o valor de uso, de troca e de posse.

Porém, o desenvolvimento inesgotável e acelerado da indústria e dos processos produtivos sob o impacto da eletrônica e da automação digital e, sobretudo, a crescente crise econômica e produtiva dos anos 70 do século 20 leva o consumo a desenvolver outros paradigmas e, dessa vez, é a informação divulgada em massa pelos veículos de comunicação interativos que estabelece para o consumidor outros padrões de exigência e, agora, é necessário estar informado, para observar e saber comprar. Agora, o consumidor não só compara, mas aprende a comprar: a lei da procura e a compara- 
ção impõem-se sobre a lógica do mercado e da oferta e o produto incorpora, à função utilitária, a informação sobre materiais, tecnologias, comportamentos, valores.

$O$ valor de posse é substituído pelo valor de seleção e se reinventa um valor de uso de outras dimensões, mais pragmático e realista, porque operado por um usuário capaz de diversificar suas necessidades e apto a processar a informação que lhe vem das próprias características básicas do desenho industrial (Ferrara, 1993, p. 198).

\section{A moda como comunicação da dinâmica industrial: da série à massa}

A moda tem uma estranha trajetória paralela à do design. Ambos são sistemas culturais e estruturas de usos e valores marcados pelo cotidiano existencial que caracteriza formas de vida econômica e estético-cultural que circulam pela sociedade e em relação às quais é possível destacar e distinguir marcas, sinais ou índices particulares. Se, para a produção industrial, o design permite distinguir a produção em série e a informação de outros valores que se incorporam ao cotidiano; a moda corresponde àquela diferença que permite criar, na série, elementos de distinção que produzem estruturas de representação e de significação capazes de definir uma posição e, sobretudo, de induzir um valor através da imagem: o vestir-se diz quem sou e aquilo que quero que pensem de mim e, isto, vai muito além da simples proteção, do ornamento ou da embalagem do corpo. A moda não é apenas aquilo que se veste, mas aquilo que mulheres e homens mostram, comunicam, olham e lêem. Assim, a moda é viva e dinâmica e nessa característica aproxima-se do design que oferece, na produção em série, a possibilidade de uma informação funcional, produtiva e estética. Estabelece-se, portanto, entre design e moda uma sinergia, uma complexa operação de integração de procedimentos e de significados que faz com que um se compare ao outro e é possível estudá-los de modo coordenado. 
Enquanto design, a moderna dimensão da moda surge exatamente no momento de inflexão que marca a passagem do valor de troca para o valor de posse e depois ao de seleção e leva a estabelecer uma distinção entre o estar na moda e o vestir-se que redimensiona uma outra maneira de pensar a produção em série e a construção massiva de um valor. Explicando.

Conforme Barthes(1967) e Simmel(1988) em obras antológicas, a moda é uma realidade institucional e social que estabelece normas independentes do indivíduo na sua singularidade. Desse modo, a moda é um registro sensível que assume o caráter de documento social da história que pode ser estudada através da evolução de estilos, tendências e práticas que caracterizam e distinguem valores e usos sociais do domínio público ao privado. Porém, nesse percurso, a moda está sujeita ao constante ultrapassar-se, ao seu declínio. Ao contrário, o vestir é a realidade através da qual o indivíduo pode apropriar-se do que está na moda para traduzi-lo ou para transforma-lo e, com isso, acabar por modificar ou mascarar a série. Para que o indivíduo se distinga da massa é necessário que, embora aderindo à produção em série, ele construa, paradoxalmente, um valor original, capaz de inovar. Há, portanto, entre a moda e o vestir uma tensão, um conflito que será intensificado ao mesmo tempo em que, na evolução da produção ao consumo em suas várias dimensões, caminhamos do valor de troca para o de seleção esbarrando no eixo deles com aquele ponto de inflexão que se define através do valor de posse.

A passagem do valor de troca para o de seleção supõe criar uma estratégia capaz de produzir, nas várias formas de repetição da moda como arte de massa, uma dialética entre o novo e o velho, entre a repetição e o original; porém o que interessa não é tanto a variação, mas a necessidade de mudança dentro de um esquema básico. Portanto, a mesma inflexão produtiva e estética que marca a passagem do valor de troca para o de posse e permite a emergência do designer nas sombras do desenhista industrial, pode ser encontrado entre a moda enquanto série pronta para o consumo e a moda como vestir de modo singular utilizando a série. Esse paralelismo vai se acentuar ao mesmo tempo em que a produção industrial fun- 
cional passa a ceder espaço para a tecnologia que informa ao propor rápida troca de valores.

Se enquanto valor de uso, a moda atendia às funções humanas básicas de proteção e agasalho, enquanto valor de troca, ela utiliza farto apelo visual e, mais do que nunca, é um código institucional e coercitivo a fim de produzir um envolvimento persuasivo capaz de gerar consumo e acumulação. Ao contrário, a passagem da troca à posse faz com que a moda abandone seu caráter normativo para transformar-se em apelo decorativo que exacerba o visual para atingir uma dimensão espetacular que cria uma história, uma fabulação comunicativa que estabelece posturas, ergonomias, trocas que confundem o industrial com o artesanal, o erótico e o recatado, o masculino e o feminino, o vestido e o despido, o formal e o informal, o insinuante e o ingênuo, o civilizado e o selvagem. Nessa dinâmica surgem as formas estruturadas ou geométricas, a verticalidade e a ampliação horizontal da figura, a seda e a renda como estereótipos da moda para datas e lugares, reforçam-se cores, sexualidade e exposição. $\mathrm{O}$ significado do vestir omite-se ante o apelo visual, sedutor e espetacular do significante e da forma (Baudrillard, 1989, p.55 e segs). A sedução caracteriza a moda do valor de posse e, nessa dimensão, ela é feminina, mesmo que se destine ao masculino.

Na posse, a moda é um imperativo e estabelece de modo descartável, o in e o out, o estar na moda ou estar fora de moda e vende ao consumidor a imagem desejada e imaginária dele mesmo feito produto e mercadoria. Desse modo, consumo, sucesso, autoestima tecem uma complicada relação de fenômenos que se misturam e são difíceis de distinguir. Por exacerbar a sensibilidade chegase a uma espécie de anestesia perceptiva que torna uniformes a invenção estética, a fruição do gosto e a oferta do mercado.

Essa fabulação espetacular é programada e se nutre de vários elementos. Assim a fotografia e os insinuantes textos da moda sustentam e preparam a exibição nos desfiles e nas passarelas. A harmonia simulada ou não entre moda e arte, é montada de tal maneira que o mercado é capaz de ignorar a produção em série e a linha de montagem e criar a ilusão do modelo único que recupera o valor mítico e singular da obra de arte. Os estilistas e seus modelos inva- 
dem os grandes e notáveis museus do mundo, como é o caso do Metropolitan de Nova York que, na década de 90, abriu suas portas para expor à visitação pública as coleções de Gianni Versace. Os figurinos com suas griffes são reforçados e divulgados pelos acessórios que são tão notáveis como os próprios modelos exclusivos e, nessa operação, invadem também o espaço que passa a ser um outro acessório igualmente assinado, ostentam o nome do estilista e seus estereótipos, cores e formas que vão do asséptico branco até o bizarro e o exótico. ou, até mesmo, à própria excentricidade visual da imagem do estilista que atua como apelo publicitário da mercadoria que produz e vende. Na mesma linha de observação, não é difícil encontrar parcerias entre artistas plásticos de renome que se associam a estilistas para criarem um plano comum de assedio visual e mútua impregnação criativa, cita-se, como exemplo, o próprio Versace que se associou a Andy Wharhol e reproduziu, em um modelo, a célebre obra de Wharhol com a reprodução de fotos de Marilyn Monroe ou o caso de Courrèges que, na década de 60 , assimilou nos tecidos e no corte dos seus modelos o abstracionismo geométrico de Mondrian; assim reproduzem-se e duplicam-se a arte e a moda. Esta programação pode ser observada em vários exemplos, porém nos casos citados, salienta-se que nada é espontâneo, tudo é planejado e programado para criar uma arte de ocasião e pronta para ser exibida no espetáculo. A sedução e a exponibilidade são as características básicas da moda como valor de posse, assim como a acumulação e a descartabilidade caracterizam o produto industrial que the corresponde.

\section{Sinergia e integração: o novo consumidor}

Porém, se a tecnologia e a crise econômica e social dos anos 70 marcaram a passagem do valor de posse para o valor de seleção, a moda como espetáculo e apelo visual atinge seu ápice no final dos anos 70 e a década de 80 é invadida pelo paroxismo produtivo que precisa pensar em tudo, do corte à venda, da produção à reprodução, à embalagem, à programação visual e à distribuição e, sobretudo, considerar a não moda ou àquele estilo vazio feito para todas as 
ocasiões que incorpora a constante mudança, visto que, agora, a moda já não pode esperar até tornar-se norma ou estilo. Estamos em um momento histórico e tecnológico marcado pela rapidez e pela mudança, o mercado precisa ser flexível e ao designer cabe ser previdente e sensível às oscilações do momento para produzir com mais agilidade a fim de adiantar-se à mudança.

O consumidor anterior passa por profunda transformação: é proprioceptivo e está atento ao próprio corpo, por isso, é capaz de receber estímulos e alertas que precisam ser respondidos através de uma ação que seleciona ofertas que considerem sua individualidade e suas necessidades. Mais do que nunca, trabalha-se em linha de montagem e em série para alcançar não o produto ou o consumo inespecífico, mas o consumidor que se transforma em prossumidor em expressão de Alvin Toffler (1980, p. 266) e preenche o momento crítico entre a produção e o consumo.

Se para o valor de troca a quantidade do produto fabricado em série era a qualidade e, se para o valor de posse, a qualidade estava na quantidade de produtos acumulados e descartáveis, para o valor de seleção, a quantidade está na oferta que exige a seleção da qualidade do produto. A antiga e vital atuação de marketing apoiado na persuasão da publicidade sedutora é reformulada e a oferta é invadida por um outro valor: comparação entre produtos e possibilidade de escolha.

A interdependência produção/consumo assinalou todas as estratégias de marketing e de publicidade do século 20 , nas décadas de 40 a 70 , dominadas por uma cultura de compromisso com o produtor à testa do processo; porém, na década de 90 , temos uma cultura dirigida pelo consumidor e vem à luz o ciberdesign calibrado e flexionado pelos processos interativos (Kerckove, 1997, p. 136) que se comunicam entre estruturas produtivas, entre mercados globais e locais e, sobretudo, entre consumidores. A competição é a tônica do momento e revela a simplicidade da lógica apoiada na lei da oferta e da procura.

Nesse torvelinho produtivo, tecnológico e, sobretudo, imaginativo, o estilista cede seu espaço à confecção, o produto único, acumulado e descartável é substituído pelo básico componível com 
claras marcas individuais. A moda que hoje já podemos rotular de antiga sofre densa e rápida mudança e seu mercado, agora, não é mais o global a ser atingido pelo fluxo de exportação, mas o consumidor interno, local, emergente e promissor, porém mais exigente porque suas condições econômicas não lhe permitem aderir ao descartável. A marca da nova moda é multiplicar para diversificar com funcional individualidade, pois o consumidor aprendeu a selecionar e a combinar. Redesenha-se com flexibilidade o mercado e o consumo, o endereço exclusivo do estilista é substituído pelas lojas de departamento e pelos shoppings onde tudo está disponível, mas misturado. A sagacidade do consumidor deve comparar e escolher. Substitui-se o distante apelo visual das passarelas pela proximidade sensível do tátil, intenso e envolvente que permite à moda encontrar-se com o design têxtil.

Ao contrário do que parece comum imaginar, o design têxtil é mais tátil do que visual e plástico e não se contenta com o apelo decorativo do desenho figurativo ou geométrico e se desenvolve entre a produção e o tecnológico, entre a moda e a inovação; misturam-se visualidade e tatilidade, ou melhor, o que se percebe no olhar emerge no tato. Nessa sinergia, moda e design se encontram para produzir uma mídia comunicativa mais sugestiva do que persuasiva: agora, o consumidor escolhe o que lhe é próprio e, de modo interativo, observa a moda que continua a propor, mas que é frágil enquanto estilo, pois já não há tempo para a construção de normas ou valores para o vestir. O corpo parece valer mais do que a moda.

Na sinergia design têxtil e moda, o designer propõe, com indispensável antecedência, alternativas visuais, táteis, técnicas, olfativas ou térmicas para produzir e multiplicar funções, associações ou combinações que são valorizadas e exploradas pela moda. Fortalece-se, portanto, a oferta não de produtos, mas de alternativas que vão da tecnologia à seleção informativa através de uma dimensão mais crítica do consumo. É possível pensar em uma tendência da moda que se apóia no vestir e se adapta ao indivíduo como realidade ergonômica, social, econômica e cultural. Estamos no território do design onde o estilista e o designer trabalham em um sistema de combinações onde tudo se concentra e se agrega em sinergia. 
Porém, essa relação comunicativa é complexa porque deve equilibrar originalidade singular com reprodutibilidade serial: estabelece-se uma regularidade entre reprodução e inovação em ritmo de controlada lentidão para poder ser seguido, mas suficientemente veloz para modular o equilíbrio do mercado entre a oferta e a demanda, entre regularidades e distinções sociais e econômicas.

Nessa complexidade, é curioso analisar o caso do jeans. Inspirado em um design têxtil de cor padrão em trama rude e na combinação entre aparência artesanal com durabilidade e custo possível para um consumidor banal; surge uma antimoda descontraída, jovem e sem preconceitos que, difundida (é originária da Itália /Gênova) nos Estados Unidos definiu, ao mesmo tempo, um modo de vida - American Way of Life - e marcou um estilo de moda que no seu redesenho do artesanal, permanece com durabilidade e é reconhecido sem ter nenhum dos requisitos tradicionais da moda. Opondo-se aos padrões recorrentes daquilo que a história havia consagrado como moda formal e desenhada, o jeans produz-se e reproduz-se. Ao sabor dos materiais contemporâneos, naturais, sintéticos ou híbridos e decorrentes de tecnologias que misturam novas texturas, fibras, fios naturais ou não, cores em matizes de azul, a moda em jeans desaparece como espetáculo visual, para ressurgir como tatilidade que ensina a ver: vê-se com as mãos e os sentidos aprendem uns com os outros.

Esse aprendizado faz o consumidor rever seu padrão de moda e, mais do que nunca, ele produz sua tendência individual através das seleções descontraídas e espontâneas; ainda que se saiba que mesmo essa alternativa é passível de ser reproduzida pela engenhosidade do mercado e pode ser transformada em um outro padrão da moda.

As últimas décadas do século 20 ensinam, para o cenário dos dias atuais, que a simbiose tecnologia e design têxtil oferece à moda uma alternativa que se adapta ao usuário trocando com ele informações térmicas, olfativas e ergonômicas e essa alternativa é vital para o desenvolvimento de um fazer produtivo que exige o redesenho da cultura do que seja a moda e, sobretudo do que é o público consumidor. Mais do que nunca, a moda é produzida em 
série para um público que deseja ser selecionado e, mais do que isso, ser individualizado. Estamos na lógica do valor de seleção e a nova moda necessita decodificar com grande sensibilidade essa cultura se quiser entender a nova linguagem cultural dos nossos dias e para a qual produz. É necessário que o design de moda se transforme em informação cultural que tem na moda tradicional um parâmetro que precisa ser superado, pois agora, já não se usa o que está em moda, ao contrário, deseja-se fazer a moda.

Nesse momento, a sinergia moda/tecnologia têxtil colocase como urgente e inevitável e implica em integrar e em estabelecer conexões produtivas. Nessa interface, a moda dialoga com o design têxtil que, no âmago dos recursos tecnológicos da reprodução, manipula variações têxteis para, com técnica, fornecer uma nova seleção de parâmetros. Integrados ao design de moda, esses parâmetros passam não mais a moldar funcionalmente o mercado, mas ao contrário, fornecem-lhe respostas que atendem ao novo consumidor que está cada vez mais individualizado e localizado, ainda que dissolvido nas multidões das grandes cidades.

Se o design tece a individualidade do cliente, o estilista modela sua aparência e trabalham em interface o designer e o estilista, o tecer e o moldar.

\section{Bibliografia}

ARGAN, Giulio Carlo. 1993. Arte Moderna. São Paulo: Companhia das Letras.

BARTHES, Roland. 1967. Système de la Mode. Paris: Seuil.

BAUDRILLARD, Jean. 1989. De La Seduction. Madrid: Catedra.

BENJAMIN, Walter. 1966. L'Opera D'Arte Nella Sua Riproducibilittà Técnica. Torino: Einaudi.

FERRARA, Lucrecia D'Alessio.1993. Olhar Periférico. São Paulo: Edusp/Fapesp.

KERKHOVE, Derrich de. 1997. A Pele da Cultura. Lisboa: Relógio D'Agua. 
LIPOVETSKY, Gilles. 1983. A Era do Vazio. Lisboa: Relógio D’Agua.

MALDONADO, Tomás. 1977. El Diseño Industrial Reconsiderado. Barcelona: Gustavo Gili (3ed. revisada e ampliada 1993. México: G. Gili)

MANZINI, Ezio. 1990. Artefatti. Verso Uma Nuova Ecologia Dell'Ambiente. Milão: Domus Academy.

ORTIZ. Renato. 2002. Ciências Sociais e Trabalho Intelectual. São Paulo: Olho D’Agua.

SENNETT, Richard. 1989. A Decadência do Homem Público. São Paulo: Companhia das Letras.

SIMMEL, Georg. 1988. La Tragédie de la Culture. Paris: Rivages.

TOFFLER, Alvin. 1980. A Terceira Onda. 19.ed. Rio de Janeiro: Record.

TOFFLER, Alvin. 1970. O Choque do Futuro. 3 ed. Rio de Janeiro: Record. 